\title{
Conf-910920--24
}

WSRC-MS-91-045

\section{EFFLUENT TREATMENT FACILITY TRITIUM EMISSIONS MONITORING(U)}

by

D. L. Dunn
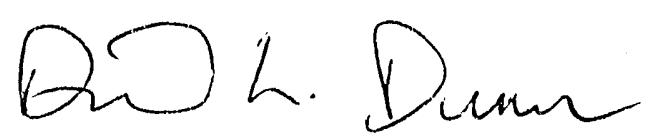

$7 / 25 / 91$
WSRC-MS- $-91-045$

DE92 009814

Westinghouse Savannah River Company

Savannah River Site

Aiken, South Carolina 29808

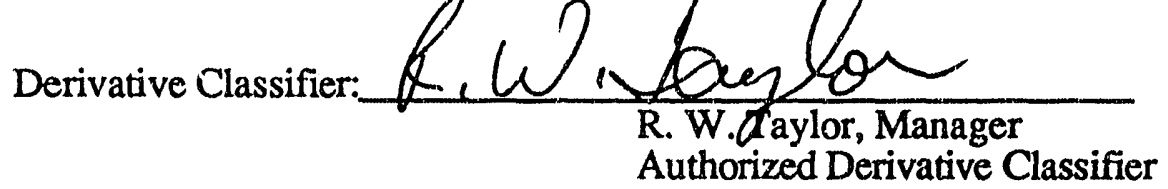

A paper proposed for presentation and publication at the

Fourth Topical Meeting on Tritium Technology in Fission, Fusion, and

Isotopic Applications

Albuquerque, New Mexico

September 29 - October 4, 1991

\section{DISCLAIMER}

This report was prepared as an account of work sponsored by an agency of the United States Government. Neither the United States Government nor any agency thercof, nor any of their employees, makes any warranty, express or implied, or assumes any legal liability or responsibility for the accuracy, completeness, or usefulness of any information, apparatus, product, or process disclosed, or represents that its use would not infringe privately owned rights. Reference herein to any specific commercial product, process, or service by trade name, trademark, manufacturer, or otherwise does not necessarily constitute or imply its endorsement, recommendation, or favoring by the United States Government or any agency thereof. The views and opinions of authors expressed herein do not necessarily state or reflect those of the United States Government or any agency thereof.

The work described in this paper was prepaned in connection with work done under Contract No. DE-AC09-89SR18035 with the U.S. Department of Energy. By acceptance of this paper, the publisher and/or recipient acknowledges the U.S. Government's right to retain a nonexclusive, royalty-free license in and to any copyright covering this paper. 


\title{
EFFLUENT TREATMENT FACILITY TRITIUM EMISSIONS MONITORING
}

\author{
D. L. DUNN \\ Westinghouse Savannah River Company \\ Savannah River Laboratory \\ Aiken, South Carolina 29808
}

\begin{abstract}
An Environmental Protection Agency (EPA) approved sampling and analysis protocol was developed and executed to verify atmospheric emissions compliance for the new Savannah River Site (SRS) $\mathrm{F} / \mathrm{H}$ area Effluent Treatment Facility. Sampling equipment was fabricated, installed, and tested at stack monitoring points for filtrable particulate radionuclides, radioactive iodine, and tritium. The only detectable anthropogenic radionuclides released from Effluent Treatment Facility stacks during monitoring were iodine-129 and tritium oxide. This paper only examines the collection and analysis of tritium oxide.
\end{abstract}

\section{INTRODUCTION}

The SRS Effluent Treatment Facility was brought on line in late October, 1988. This fulfilled a Resource Conservation and Recovery Act (RCRA) mandate that banned the use of SRS seepage basins after November 8, 1988. The facility was designed to collect and treat water previously discharged to the $\mathrm{F}$ - and $\mathrm{H}$ - area seepage basins. The facility receives routine process wastewater, reactor fuel reprocessing cooling water, and waste tank storm runoff water. It removes radioactive and nonradioactive contaminants, except tritium, from process effluents. This allows the water to be discharged to Upper Three Runs Creek, which empties into the Savannah River. The process eliminates the use of seepage basins, which adversely impact the quality of groundwater. The EPA construction/operation approval for the Effluent Treatment Facility required a series of stack effluent tests within 90 days of facility startup. The sampling protocol included in this report was first defended through Department of Energy (DOE) review and was then approved by the EPA.

Two stacks of the Effluent Treatment Facility were monitored during December, 1988 through January, 1989. The control building stack, which handled laboratory hood exhausts, was designed with one Kurz ${ }^{\circledR}$ isokinetic sampling port and was monitored first for tritium and iodine-129. The treatmerıt building stack, which managed process gas exhaust was monitored simultaneously through two Kurz isokinetic sampling ports for particulate radionuclides. Each stack was monitored continuously for three weeks by each sampling system.

\section{PROCEDURES}

Residual moisture from the manufacturing process was removed from commercial molecular sieve, Davison type $4 \mathrm{~A}$, by heating batches of sieve to $500^{\circ} \mathrm{C}$. Diryness was verified by adding an accurately known weight of water to the sieve and then quantitatively recovering the water at the conclusion of the drying process. If the weight of the recovered water was not within $5 \%$ of the water added, the sieve was rejected and detained for another drying cycle.

Dry adsorbent was sealed in furnace glassware and stored in a low humidity, tritium free area until use. Samplers were filled with dry adsorbent inside this low 
humidity, tritium free area. Atmospheric tritium was removed from the air supplied to the room by passing building air in series through a water scrubber, activated molecular sieve beds, and finally HEPA filters. Relative humidity, typically $7 \%$, was monitored continuously to verify equipment operation. The air stream conducted into the room was sampled during all sieve material transfers to verify background conditions. The filled collection canisters were sealed to prevent intrusion of ambient tritium oxide during transport to the collection site.

Isokinetic sampling systems designed by Kurz were installed in the exhaust systems of the control and treatment buildings at the Effluent Treatment Facilities. Portable collection equipment for tritium oxide was connected as shown in Figure 1 to the Kurz sampling system to insure that the collected samples adequately represented facility releases. The tritium oxide sampler, shown schematically in Figure 1, required a flow rate of only 1 liter per minute (lpm). The tritium collection system had little effect on the full flow (nominally $85 \mathrm{lpm}$ ) through

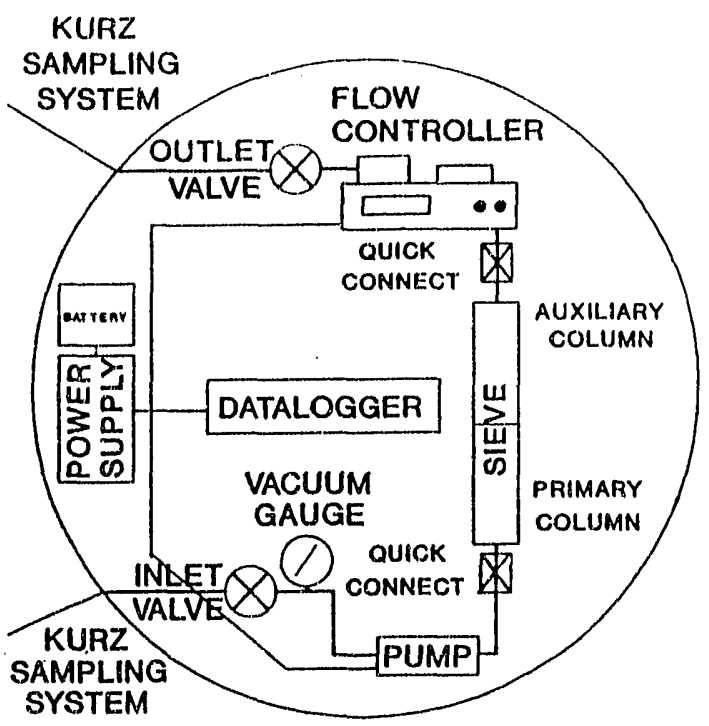

Fig. 1. Flow schematic of the Effluent Treatment Facility Tritium Monitoring System. the Kurz sampling system. After passing through the collection systems, the sampled air streams were redirected to the exhaust stack.

The molecular sieve adsorbed water vapor containing tritium oxide, HTO, from the sampled air stream. A downstream auxiliary column also containing molecular sieve was used to collect any water that persisted in the air stream leaving the primary column. The $1 \mathrm{lpm}$ sampling rate was regulated by a mass flow controller. The flow rate was continuously recorded in a data logger to provide accurate air volumes over the duration of the 24 hour collection period.

The collection canister was a double chambered stainless steel cylinder. The primary adsorbent column was in the first chamber and the backup adsorbent was immediately downstream in the adjacent chamber. The two chambers were separated by a screen to prevent mixing of adsorbent.

The collection canister was changed daily. To change the adsorbent column, air flow through the tritium collection system was first valved off at the inlet and outlet valves of the system. The used column was removed and then sealed to preserve sample integrity during transport to the analysis lab. Sample collection parameters accumulated by the data logger were transferred to tape for later retrieval.

After installation of a new collection canister, the system was checked for air leaks by first opening the inlet and outlet valves and allowing the system vacuum to stabilize, indicated by a vacuum gauge mounted downstream of the system inlet valve. The system inlet and outlet valves were then closed to isolate the vacuum in the sampling system. If the isolated vacuum remained constant for one minute, the system was considered leak free. The system was then opened for collection and the data logger was initiated. After the collection period, the leak check was repeated to verify the integrity of the collected sample. 
Canisters were returned to the laboratory and the sieve material was unloaded into clean, dry sample snecific glass vessels. These vessels containing sieve material with physically adsorbed sample were transferred to a furnace, connected to a vacuum manifold and evacuated to 500 microns. The furnace temperature was raised slowly from an initial $300^{\circ} \mathrm{C}$ to $500^{\circ} \mathrm{C}$ and held constant there for 24 hours. The entrained water slowly desorbs. After several hours at $500^{\circ} \mathrm{C}$, three grams of tritium free water were introduced into the vessels to aid desorbtion of the original sample. Freeze traps, immersed in an ethylene glycol solution and maintained at $-40^{\circ} \mathrm{C}$ or colder, were downstream of the furnace. The desorbed sample water and the additional three grams of expurgating water were crystallized onto the cold surface of a connected trap. After 24 hours, the freeze traps were removed, capped, and allowed to warm to room temperature. Recovered sample water weights were then carefully recorded and the trap contents transferred to sample vials. The original sample weight was the total recovered weight less the freeze trap weight and the three grams of additional water.

A three gram subsample of the recovered sample was diluted into a scintillation vial containing liquid scintillation cocktail mix. The tritium concentration was measured by counting the aliquot in a Tri-Carb® 2000 CA/LL liquid scintillation analyzer. The analyzer was calibrated as needed with NIST and NIST traceable standards. Appropriate calibration standards and blanks were analyzed with each suite of samples to verify calibrations and background.

\section{RESULTS}

Tables 1 and 2 list the daily releases of tritium oxide through the monitored stack. The releases shown in the tables reflect the combined values from the primary and auxiliary adsorbent columns. Typically, greater than $99 \%$ of the total tritium in the combined sample was collected on the primary column.

TABLE 1

EFFLUENT TREATMENT FACIUTY CONTROL BUILDING STACK

\begin{tabular}{l} 
ON \\
DATE \\
\hline 14DEC88 \\
15DEC88 \\
16DEC88 \\
17DEC88 \\
18DEC88 \\
19DEC88 \\
20DEC88 \\
21DEC88 \\
22DEC88 \\
23DEC88 \\
24DEC88 \\
25DEC88 \\
26DEC88 \\
27DEC88 \\
28DEC88 \\
29DEC88 \\
30DEC88 \\
31DEC88 \\
O1JAN89 \\
O2JAN89 \\
O3JAN89
\end{tabular}

\begin{tabular}{r} 
CONCENTRATION \\
PCi/m3 \\
\hline 237.29 \\
429.76 \\
141.39 \\
478.47 \\
411.04 \\
137.59 \\
809.86 \\
421.35 \\
94.27 \\
1010.41 \\
279.86 \\
1000.13 \\
111.97 \\
101.44 \\
499.16 \\
124.17 \\
255.14 \\
230.86 \\
1657.45 \\
349.70 \\
1567.26
\end{tabular}

MILLICURIESS RELEASED PER COLLECTION PERIOD 0.078

0.144

0.046

0.161

0.139

0.046

0.271

0.142

0.031

0.338

0.093

0.336

0.039

0.033

0.165

1).042

0.084

0.077

0.554

0.117

0.524 
TABLE 2

\section{EFFLUENT TREATMENT FACILITY TREATMENT BUILDING STACK}

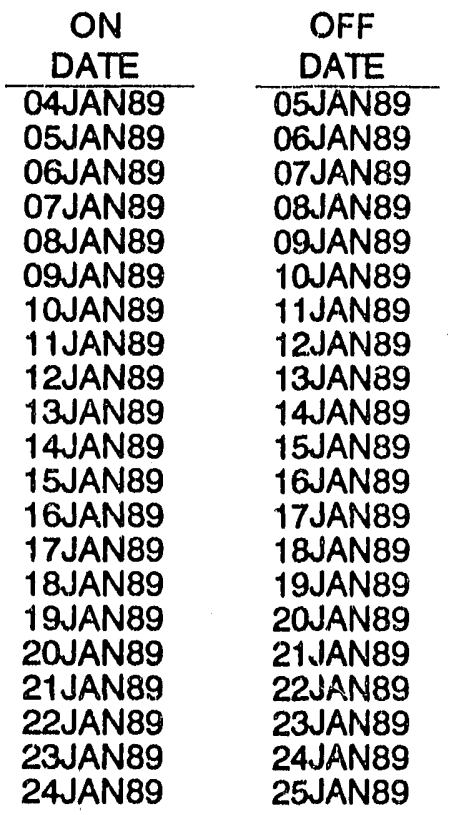

\begin{tabular}{r} 
CONCENTRATION \\
PCi/m3 \\
\hline 1639 \\
922 \\
973 \\
969 \\
1431 \\
395 \\
452 \\
437 \\
787 \\
677 \\
466 \\
1378 \\
2111 \\
1555 \\
1057 \\
20746 \\
1743 \\
2612 \\
1878 \\
2042 \\
1872
\end{tabular}

\begin{tabular}{c} 
MILLICURIES RELEASED \\
PER COLLECTION PERIOD \\
\hline 2.454 \\
1.455 \\
1.477 \\
1.495 \\
2.219 \\
0.559 \\
0.725 \\
0.667 \\
1.255 \\
0.987 \\
0.714 \\
2.175 \\
3.239 \\
2.579 \\
1.736 \\
30.390 \\
2.731 \\
3.744 \\
2.838 \\
3.046 \\
2.770
\end{tabular}

Tritium releases ranged from 0.03 to 0.55 millicuries per day from the Control building stack and from 0.56 to 30.39 millicuries per day from the Treatment building stack. The total tritium released from the Control building stack during the three week monitoring period was 3.5 millicuries. The total tritium released from the Treatment building stack was 69.3 millicuries during the second three week monitoring period.
On all monitoring days except one, the releases from the Treatment building stack fell in the range of 0.56 to 3.74 millicuries per day. On the single exception day, the release was 30.39 millicuries. The fluctuation cannot be attributed to a known anomaly in the process. Tritium emissioris, through the treatment building stack, averaged 20 times higher than those through the control building stack during sampling. These data are shown graphically in Figures 2 and 3. 


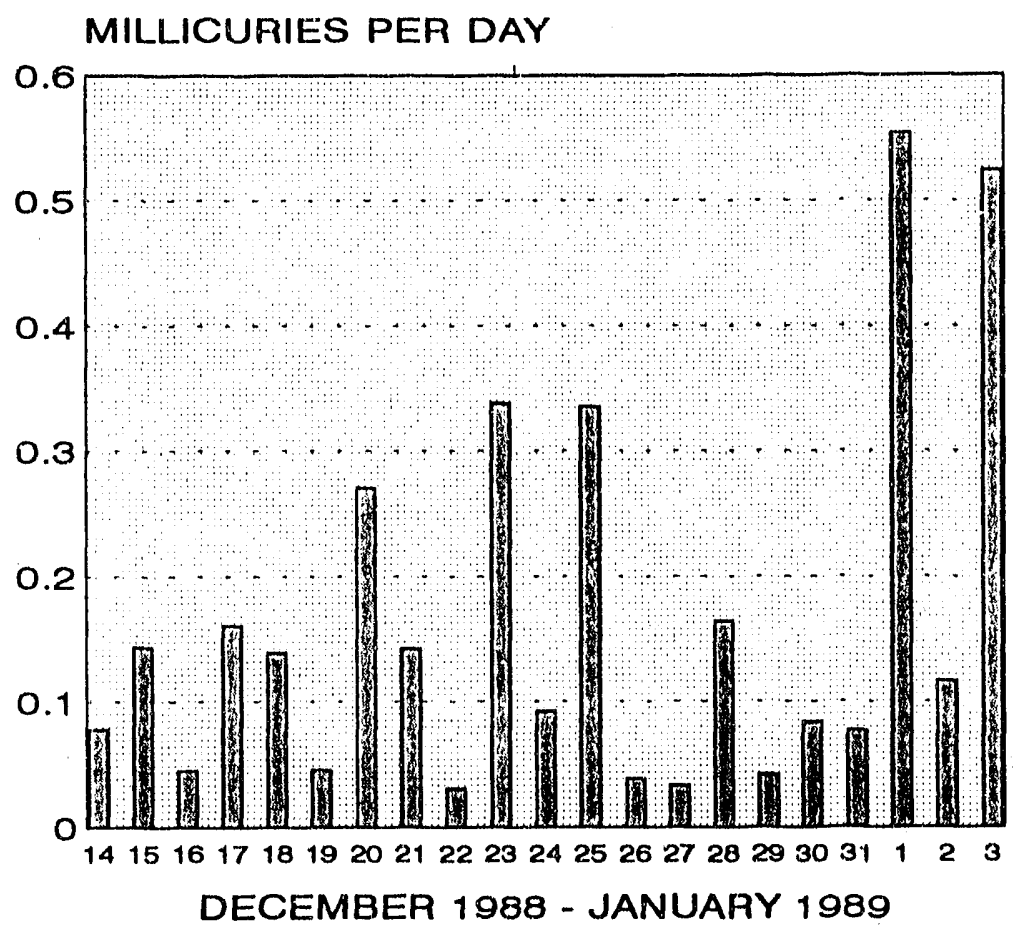

Fig. 2. Control Building Stack Monitoring Results

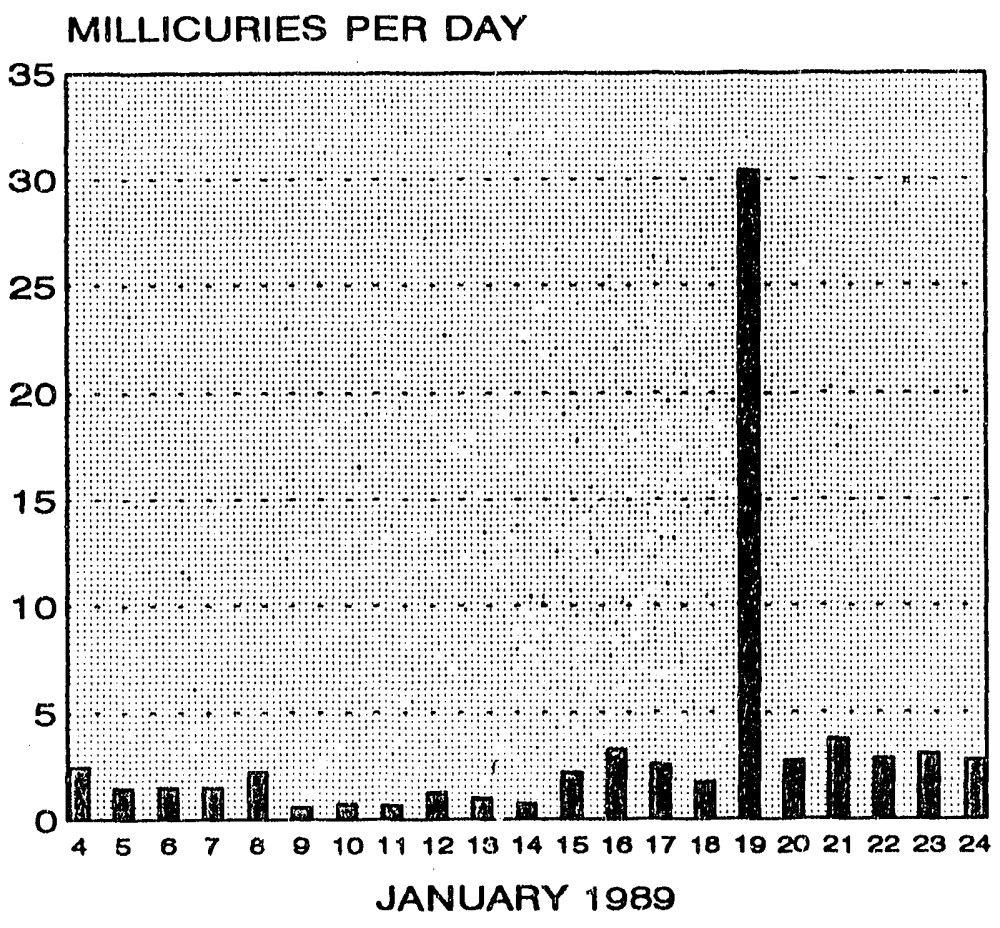

Fig. 3. Treatment Building Stack Monitoring Results 


\section{DISCUSSION}

The Effluent Treatment Facility uses a series of water treatment processes including $\mathrm{pH}$ adjustment, microfiltration, organic removal, reverse osmosis, and ion exchange. Secondary liquid wastes are concentrated by evaporation. The evaporated vapor is released through the building stacks after treatment by ion exchange.

A major design criterion for the Effluent Treatment Facility was secondary waste minimization. The reverse osmosis unit, for example was designed to produce $90 \%$ permeate for ion exchange and evaporation. Successful startup of the Effluent Treatment Facility required confirmation of effectual ion exchange cleanup of the stack releases of high separation permeate.

All sampling and analysis for tritium oxide occurred without incident or procedural discrepancy.

\section{CONCLUSIONS}

The SRS F/H area Effluent Treatment Facility met or bettered the radionuclide emissions requirements of applicable NESHAP licensing permits at facility startup.

\section{ACKNOWLEDGMENTS}

The author would like to thank J. R. Aggus for his help in designing the sampler and adapting it to the existing Kurz sampling system. Sieve handling and sampler maintenance were performed by $C$. E. Summer, J. D. Shuford, B. M. Lawrence, H. L. Hayes, and R. R. Penix. Appreciation is expressed to R. W. Taylor for his coordination and leadership of all radionuclide emissions monitoring by the Environmental Technology Section.

The Environmental Technology Section and the Environmental Sciences Section of the Savannah River Laboratory conduct ongoing environmental management and research programs in support of the Effluent Treatment Facility as well as other SRS operations. Independent environmental studies of post-operational characteristics of Upper Three Runs Creek waters and fish populations are being conducted by the Savannah River Ecology Laboratory, operated by the University of Georgia under contract with DOE. The Environmental Monitoring Section of the Environmental Protection Department conducts extensive sampling programs in support of SRS environmental compliance activities.

The work described in this paper was prepared in connection with work done under Contract No. DE-AC09-89SR18035 with the U.S. Department of Energy. 

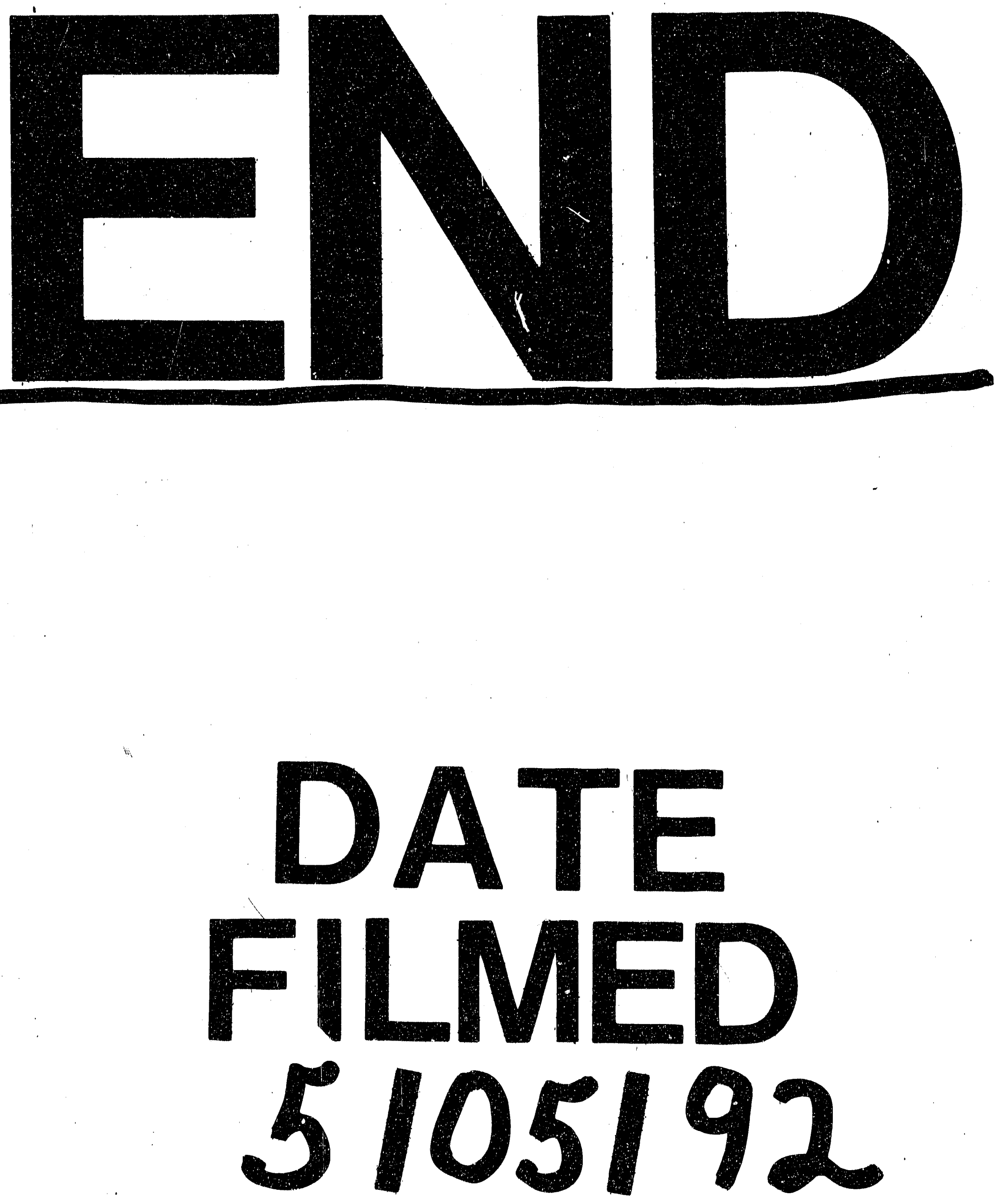
